\section{FBl's case for genetics}

SIR - Your article "FBI gives in on genetics" (Nature 355, 663, 1992) is incorrect in its representation of the purpose of our recent collection of population frequency data from several European forensic laboratories.

Since the inception of the Federal Bureau of Investigation's DNA programme, our scientists have been engaged in a continuous assessment of the issues raised by DNA typing and its forensic application. The data that have been collected (some published in the scientific literature and some unpublished) are but further evidence of the reliability and validity of the FBI's estimates of the likelihood that a particular multilocus DNA profile will occur.

Whether using general population data for Caucasians, African Americans, Hispanics and Orientals, or for subgroups of these populations, it is generally accepted in the scientific community that an individual multilocus DNA profile is extremely rare and therefore highly informative for individual identification. Even so, the FBI has never assumed that there are no differences between subpopulations, but rather has taken a conservative approach that minimizes the effect of such differences as there may be between subpopulations.

The European and other population data we have been collecting are not new to forensic scientists who attend the appropriate meetings. Our experience with such data forms the knowledge base on which is founded our.confidence that subpopulations are not an impediment to the calculation of valid frequency estimates for DNA profiles.

The recent trip by FBI scientists to European and other laboratories was not undertaken in order to "re-examine those assumptions (of heterogeneity)", but was an attempt to accommodate those few critics of DNA profiling who suggest that the subpopulation issue is a source of concern.

Your article also suggests that incompatible laboratory standards in various countries could vitiate comparisons, but that statement does not acknowledge the international collaboration on DNA typing protocols that has been under way since 1988, notably by the Technical Working Group on DNA Analysis and Methods in the United States and the European DNA Program. This collaboration is but a further indication of the worldwide consensus which now exists on the methods and population sampling approaches in forensic DNA testing.

\section{John H. Hicks}

US Department of Justice,

Federal Bureau of Investigation,

Washington, DC 20535, USA

\title{
Ethical problems in the genes
}

SIR - The leading article "Genetics and the public interest" (Nature 356, 365; 1992) ends with the declaration: "the present spate of new knowledge in human genetics deserves the warmest welcome". Truly so, in terms of what it can tell us about the human condition and to help in understanding and alleviating human suffering. But not if some of the views you express are to become the basis for dealing with those who in the natural lottery of inheritance have drawn defective genes. What norm of fairness does your leader writer abide by that equates the self-inflicted risks associated with smoking with the hapless inheritance of aberrant genes? That your journal could make such a comment suggests to me that this issue of justice has not been adequately addressed by society in general or by bioethicists in particular.

If the natural lottery of inheritance is seen as "merely unfortunate" and not "unfair", there is no moral imperative for society to care for those with aberrant genes and their phenotypic expression. What guarantee, then, that "liberal societies should acknowledge an obligaNATURE · VOL 357 • 4 JUNE 1992

\section{Interest in CNR}

SIR - I was granted a fellowship by the European Communities to carry out experimental research in the field of molecular biology at a CNR (Consiglio Nazionale delle Ricerche) institute in Milan from 1991 to 1992.

Since January, my monthly salary, $1,938 \mathrm{ECU}$, and a bench fee of 5,000 ECU for the host institution have been sent to CNR headquarters in Rome quarterly, but the money has not yet reached its destination, the fellowship holder. I have been sustained partly by support from private companies, partly from the budget of the laboratory here in Milan. My monthly income has been highly unpredictable and I have not been paid in full.

This, apparently, is not an uncommon occurrence. CNR fellowship holders can wait several months before receiving any money at all and reimbursement of expenses for travels, conferences and so on may take longer than a year.

My question is: who is receiving the interest on this money, and when will somebody take an interest in changing this situation, which borders on theft?

Gertrud Lund

IBV, 15 Via Bassini,

20133 Milan, Italy

\section{Not by numbers}

SIR - It was a nice coincidence that Lord Kelvin's old chestnut "when you cannot express it in numbers, your knowledge is of a meagre and unsatisfactory kind" should appear on your Correspondence page (Nature 356, 653; 1992) next to a letter by Stephen Jay Gould (albeit on a different subject) who so elegantly refuted in Wonderful Life such a narrow view of science: "We will never be able to appreciate the full range and meaning of science until we shatter the stereotype of ordering by status and understand the different forms of historical explanation as activities equal in merit to anything done by physics and chemistry. . . . The answer to such questions as 'Why can humans reason?' lies as much (and as deeply) in the quirky pathways of contingent history as in the physiology of neurons."

\section{J. R. Parker}

Shell-Mex House,

Strand, London WC2R ODX, UK

SIR - Science explains the maximum number of phenomena with the minimum number of hypotheses.

Brennig James

Cherry Orchard,

Marlow Common,

Bucks SL7 2QP, UK 